\title{
Comparison of Incidence of Urinary Tract Infection in Diabetic vs Non-Diabetic and Associated Pathogens
}

\author{
Sonam Ramrakhia ${ }^{1,2}$, Kunal Raja ${ }^{3}$, Kapeel Dev ${ }^{4}$, Ajay Kumar ${ }^{5}$, Vinesh Kumar ${ }^{6}$, Besham Kumar $^{7}$ \\ 1. Medicine, Liaquat University of Medical and Health Sciences, Sukkur, PAK 2. Medicine, Mustafai Trust Central \\ Hospital, Sukkur, PAK 3. Internal Medicine, Shaheed Mohtarma Benazir Bhutto Medical University, Larkana, PAK 4. \\ Internal Medicine, Ghulam Muhammad Mahar Medical College, Sukkur, PAK 5. Internal Medicine, Jinnah Sindh \\ Medical University, Karachi, PAK 6. Internal Medicine, Ghulam Mohammad Mahar Medical College, Sukkur, PAK 7. \\ Internal Medicine, Jinnah Postgraduate Medical Centre, Karachi, PAK
}

Corresponding author: Sonam Ramrakhia, sonam.ramrakhia@gmail.com

\section{Abstract}

\section{Introduction}

Urinary tract infections (UTIs) are common in low socioeconomic country like Pakistan. There are various factors responsible for UTI, one major factor being diabetes. This study aims to compare diabetic and nondiabetic patients, for gender association, symptoms, and organisms, with UTI.

\section{Methods}

This cross-sectional study was conducted in the medicine ward of tertiary care hospital in Pakistan from January 2019 to December 2019. For urine analysis, freshly voided 5-10 ml of clean midstream urine specimens was collected in a sterile container. Samples were sent to the lab immediately, A colony count of $\geqslant 10^{5} \mathrm{CFU} / \mathrm{ml}$ was considered for the diagnosis of UTI. Culture was done if UTI was diagnosed.

\section{Results}

The overall incidence of UTI in participants of the diabetic group was significantly higher than those in the non-diabetic group ( $13.67 \%$ vs $6.40 \%$; $\mathrm{P}=0.004$ ). Escherichia coli was the most common organism in both the diabetic and non-diabetic groups ( $60 \%$ vs $72 \%$; $\mathrm{P}=0.73$ ). Frequency of Klebsiella was considerably higher in the participants of diabetes but it was not significant $(23.3 \%$ vs $11.1 \%$; $\mathrm{P}=0.29)$.

\section{Conclusion}

UTI was significantly higher in the diabetic population compared to the non-diabetic population. Since diabetes is prevalent in Pakistan, care of diabetes should include reducing the risk factors for UTI.

Review began 09/10/2020 Review ended 09/14/2020 Published 09/17/2020

\section{() Copyright 2020}

Ramrakhia et al. This is an open access article distributed under the terms of the Creative Commons Attribution License CC-BY 4.0., which permits unrestricted use, distribution, and reproduction in any medium, provided the original author and source are credited.
Categories: Endocrinology/Diabetes/Metabolism, Internal Medicine Keywords: diabetes mellitus, urinary tract infection, pakistan

\section{Introduction}

Urinary tract infection (UTI) is common and is usually caused by bacteria [1]. There are many causes of UTI, of which diabetes is one of the potential reasons of UTI [2], which occurs due to alteration in the immunity of diabetic patients like granulocyte dysfunction [3]. Studies have suggested that the pathogens cause UTI to adhere to the uroepithelial cells resulting in impaired intracellular calcium metabolism $[4,5]$.

Patients may or may not elicit signs and symptoms depending upon the infection severity [6]. Patients suffering from UTI complain of nausea, vomiting, fatigue, spiking fever, chills, dysuria, urinary frequency, urgency, lower abdominal/flank/back pain, and, in severe cases, altered levels of consciousness [7]. UTI can be classified based on its location (upper and lower) and severity (uncomplicated and complicated). Uncomplicated UTI is relatively mild, occurs more commonly in females, and does not necessitate treatment through antibiotic therapy [8]. Complicated UTI has relatively severe signs and symptoms and is not easy to treat [9]. Recurrence of UTI is common either through the same microorganism's involvement, which causes relapse, or re-infection by a different microorganism [10-12]. Common pathogens involved are Escherichia coli, Klebsiella spp., Mycoplasma spp., Enterobacter spp., Staphylococcus aureus, Candida albicans, and worms like threadworms, flukeworms, etc. Of these, E. coli is the most common cause of UTI $[13,14]$.

Various factors increase the risk of UTI, including diabetes mellitus. UTI in patients with diabetes is more severe and has more complication. Various factors contribute to an increase in frequency of UTI in diabetes, including weak immune system, neuropathy, and poor metabolic control [15]. 


\section{Cureus}

To our knowledge, there is no study available that analyzes the difference in the treatment of UTI among diabetic and non-diabetic patients. Therefore, through this study, we plan to compare the pathogens causing UTI in diabetic and non-diabetic patients, which will help physicians modify their treatment strategies for UTI depending upon the presence or absence of comorbidity like diabetes in the future.

\section{Materials And Methods}

This cross-sectional study was conducted in the medicine ward of tertiary care hospital in Pakistan from January 2019 to December 2019. A total of 1,074 participants were included in the study, including 512 diabetic patients and 562 non-diabetic caregivers of diabetic patients. Participants who took any antibiotics for the last 14 days during data collection were excluded. Patients' demographics, symptoms, and diabetes status were recorded in a self-structured questionnaire.

For urine analysis, freshly voided 5-10 $\mathrm{ml}$ of clean midstream urine specimens was collected in a sterile container. Samples were sent to the lab immediately, where they were analyzed. A colony count of $\geqslant 10^{5}$ $\mathrm{CFU} / \mathrm{ml}$ was considered for the diagnosis of UTI [16]. Urine of participants with colony count of $\geqslant 10^{5} \mathrm{CFU} / \mathrm{ml}$ was sent for urine culture for identification of organism.

The analysis of data was done using the SPSS statistical software package version 23 (IBM Corp., Armonk, $\mathrm{NY}$ ). Numerical data such as age were presented as mean and standard deviation. Percentage and frequency were used to present symptoms, gender, diabetic status, and organism. The chi-square test was used to compare the two groups. A p-value of less than 0.05 meant that there is a difference between the two groups, and the null hypothesis is void.

\section{Results}

A total of 1,074 participants were included, who were randomized into two groups: diabetic $(\mathrm{n}=512)$ and non-diabetic group $(\mathrm{n}=562$ (Table 1$)$.

\begin{tabular}{|c|c|c|}
\hline Demographics & Diabetes $(n=512)$ & Non-Diabetes $(n=562)$ \\
\hline Gender: male, female & 224 (43.75\%), 288 (56.25\%) & 250 (44.48\%), 312 (55.51\%) \\
\hline Age & $46 \pm 11$ & $51 \pm 13$ \\
\hline HbA1c & $7.08 \pm 2.24$ & $4.91 \pm 1.06$ \\
\hline \multicolumn{3}{|c|}{ TABLE 1: Patients' Demographics } \\
\hline \multicolumn{3}{|l|}{ HbA1c, hemoglobin A1c } \\
\hline
\end{tabular}

The overall incidence of UTI in participants of the diabetic group was significantly higher than those in the non-diabetic group (13.67\% vs $6.40 \%$; $\mathrm{P}=0.004)$. Females had higher proportion of UTI incidence compared to males (10.6\% vs $8.8 \%)$; however, when stratified for diabetes status, the result was not significant (Table 2).

\begin{tabular}{|c|c|c|c|}
\hline Incidence of UTI & Diabetes & Non-Diabetes & P-value \\
\hline Total & $70(13.67 \%)$ & $36(6.40 \%)$ & $0.004^{\star}$ \\
\hline Males & $26(11.60 \%)$ & $16(6.40 \%)$ & \multirow{2}{*}{$0.52^{\star \star}$} \\
\hline Females & 44 (15.27\%) & 20 (6.41\%) & \\
\hline
\end{tabular}

\section{TABLE 2: Incidence of Urinary Tract Infection (UTI)}

* means significant result, ** means non-significant result

Fever and dysuria were significantly higher in patients with diabetes compared to non-diabetic patients. There was no significant difference in any symptom (Table 3). 


\section{Cureus}

\begin{tabular}{|c|c|c|c|}
\hline Symptoms & Diabetes $(n=70)$ & Non-Diabetes $(n=36)$ & P-value \\
\hline Fever & 46 (65.7\%) & $12(61.11 \%)$ & $0.02^{\star}$ \\
\hline Dysuria & $34(48.55 \%)$ & $6(50.0 \%)$ & $0.023^{x}$ \\
\hline Increased frequency & $18(25.71 \%)$ & $10(27.77 \%)$ & $0.86^{\star \star}$ \\
\hline Abdominal pain & $16(22.85 \%)$ & $10(27.77 \%)$ & $0.93^{\star \star}$ \\
\hline Vomiting & $6(8.57 \%)$ & $4(11.1 \%)$ & $0.92^{\star \star}$ \\
\hline Hematuria & $4(5.71 \%)$ & $2(5.55 \%)$ & $0.87^{\star \star}$ \\
\hline Pyuria & $8(11.42 \%)$ & 4 (11.11\%) & $0.82^{\star \star}$ \\
\hline Incontinence & $18(25.71 \%)$ & $10(27.77 \%)$ & $0.86^{\star \star}$ \\
\hline Retention & $16(22.85 \%)$ & $4(11.11 \%)$ & $0.30^{\star \star}$ \\
\hline
\end{tabular}

\section{TABLE 3: Symptoms of Urinary Tract Infection}

* means significant result, ** means non-significant result

E. coli was the most common organism in both diabetic and non-diabetic groups. The frequency of Klebisella was considerably higher in the participants of diabetes but it was not significant (Table 4).

\begin{tabular}{|c|c|c|c|}
\hline Organisms & Diabetes $(n=70)$ & Non-Diabetes $(n=36)$ & P-value \\
\hline Escherichia coli & $36(60.0 \%)$ & $26(72 \%)$ & $0.73^{\star x}$ \\
\hline Klebisella & $14(23.3 \%)$ & $4(11.1 \%)$ & $0.29^{\star \star}$ \\
\hline Enterococcus & $2(3.3 \%)$ & 0 & $0.54^{\star \star}$ \\
\hline Pseudomonas & $2(3.3 \%$ & $4(11.1 \%)$ & $0.28^{\star \star}$ \\
\hline Coagulase-positive Staphylococcus & $2(3.3 \%)$ & 0 & $0.54^{\star \star}$ \\
\hline Others & $4(6.6 \%)$ & $2(5.5 \%)$ & $0.87^{\star \star}$ \\
\hline
\end{tabular}

\section{TABLE 4: Organisms Identified in Culture}

NA, not applicable

${ }^{\star \star}$ means non-significant result

\section{Discussion}

Diabetic patients are more prone to develop UTI as compared to non-diabetic patients. There are many mechanisms that may explain the higher prevalence of UTI in diabetic patients. Studies suggest that high glucose levels in urine aid in the growth of uropathogens [17]. Complications such as emphysematous pyelonephritis develop due to higher glucose levels in renal parenchyma, creating a favorable environment for bacterial colonization [18]. Higher glucose levels may disturb humoral, innate, and cellular immunity. They may also cause bladder dysfunction due to autonomic neuropathy, leading to urinary retention and stasis $[19,20]$.

Our results show that UTI is more prevalent in females than in males due to short urethra and its proximity to anal canal [21]. Family history, i.e. UTI in first-degree relatives, plays a role in the development of recurrent UTI and pyelonephritis in females, which can be explained by genetic factors involving immunological response against uropathogens. Change in normal flora of vagina that decreased $\mathrm{pH}$ levels of the vagina may also contribute to UTI [22].

In our study, when we compared the symptoms of UTI between diabetic and non-diabetic patients, we observed that diabetic patients had relatively higher fever and dysuria, while other symptoms were similar 
in both the groups. This is inconsistent with Garg study in 2015, according to which fever, dysuria, pain abdomen, vomiting, hematuria, storage, and voiding were significantly higher in the diabetic group compared to the non-diabetic group [23].

In this study, the most common organism that causes UTI is E. coli, both in diabetic and non-diabetic participants. This organism adheres to urothelial cells by anchoring to glycolipid present on their cell membrane through P fimbriae [24]. P fimbriae is composed of many subunits, the most essential of these is FimH as it helps in invading the urothelial cells and adhesion to glycoprotein containing mannose compounds [25].

The risk of developing UTI in diabetic and in non-diabetic groups is different because of many reasons, a few of which have been listed above, which is why it is necessary to recognize these risk factors. Identifying these risk factors will help us prevent complications related to UTI in patients with diabetes.

\section{Conclusions}

In our study, UTI was significantly higher in patients with diabetes and in female patients. The clinical symptoms of dysuria and pain abdomen were more significant in diabetic females. E. coli was the most common isolate in both groups, followed by Klebsiella. A thorough watch and aggressive outpatient management of a diabetic patient who presents with simple UTI can prevent progression to more dreaded complications and associated morbidity and mortality.

\section{Additional Information \\ Disclosures}

Human subjects: Consent was obtained by all participants in this study. Ghulam Muhammad Mahar Medical College issued approval GMMMC/1118/13-C. Animal subjects: All authors have confirmed that this study did not involve animal subjects or tissue. Conflicts of interest: In compliance with the ICMJE uniform disclosure form, all authors declare the following: Payment/services info: All authors have declared that no financial support was received from any organization for the submitted work. Financial relationships: All authors have declared that they have no financial relationships at present or within the previous three years with any organizations that might have an interest in the submitted work. Other relationships: All authors have declared that there are no other relationships or activities that could appear to have influenced the submitted work.

\section{References}

1. Gul F, Bacha N, Khan Z, Khan SA, Mir A, Amin I: Characterization and antibiotic susceptibility pattern or uropathogens from Khyber Pakhtunkhwa, Pakistan. J Med Sci. 2017, 25:153-157.

2. Woldemariam HK, Geleta DA, Tulu KD, Aber NA, Legese MH, Fenta GM, Ali I: Common uropathogens and their antibiotic susceptibility pattern among diabetic patients. BMC Infect Dis. 2019, 19:43. 10.1186/s12879-018-3669-5

3. Jha PK, Baral R, Khanal B: Prevalence of uropathogens in diabetic patients and their susceptibility pattern at a tertiary care center in Nepal: a retrospective study. Int J Biomed Lab Sci. 2014, 3:29-34.

4. Abdul-Sahib KY: Study of ciprofloxacin resistant Escherichia coli (CREC) in type 2 diabetic patients with symptomatic urinary tract infection. Iraq J Comm Med. 2008, 21:58-63.

5. Baqai R, Aziz M, Rasool G: Urinary tract infection in diabetic patients and biofilm formation of uropathogens. Infect Dis J Pak. 2008, 17:7-9.

6. Schnarr J, Smaill F: Asymptomatic bacteriuria and symptomatic urinary tract infections in pregnancy . Eur J Clin Invest. 2008, 38:50-57. 10.1111/j.1365-2362.2008.02009.x

7. Hamdan HZ, Kubbara E, Adam AM, Hassan OS, Suliman SO, Adam I: Urinary tract infections and antimicrobial sensitivity among diabetic patients at Khartoum, Sudan. Ann Clin Microbiol Antimicrob. 2015, 14:26. 10.1186/s12941-015-0082-4

8. Mehnert-Kay SA: Diagnosis and management of uncomplicated urinary tract infections . Am Fam Physician. 2005, 72:451-456

9. Nicolle LE: Complicated urinary tract infection in adults . Can J Infect Dis Med Microbiol. 2005, 16:349-360. $10.1155 / 2005 / 385768$

10. Behzadi P, Behzadi E, Yazdanbod H, Aghapour R, Akbari Cheshmeh M, Salehian Omran D: A survey on urinary tract infections associated with the three most common uropathogenic bacteria. Maedica (Buchar). 2010, 5:111-115.

11. Behzadi PE, Behzadi E: Evaluation of UVB light efficacy for inducing apoptosis in Candida albicans cultures . Roum Arch Microbiol Immunol. 2012, 71:39-42.

12. Hooton TM: Recurrent urinary tract infection in women . Int J Antimicrob Agents. 2001, 17:259-268. 10.1016/s0924-8579(00)00350-2

13. Ganesh R, Shrestha D, Bhattachan B, Rai G: Epidemiology of urinary tract infection and antimicrobial resistance in a pediatric hospital in Nepal. BMC Infect Dis. 2019, 19:420. 10.1186/s12879-019-3997-0

14. Hu W, Xie S, Yu F, Hao W: Characteristics of pathogens and mortality predictors of older Chinese patients with nosocomial urinary tract infections. Geriatr Gerontol Int. 2019, 19:541-546. 10.1111/ggi.13661

15. Nitzan O, Elias M, Chazan B, Saliba W: Urinary tract infections in patients with type 2 diabetes mellitus: review of prevalence, diagnosis, and management. Diabetes Metab Syndr Obes. 2015, 8:129-136. 10.2147/DMSO.S51792 
16. Schmiemann G, Kniehl E, Gebhardt K, Matejczyk MM, Hummers-Pradier E: The diagnosis of urinary tract infection: a systematic review. Dtsch Arztebl Int. 2010, 107:361-367. 10.3238/arztebl.2010.0361

17. Wang MC, Tseng CC, Wu AB, Lin WH, Teng CH, Yan JJ, Wu JJ: Bacterial characteristics and glycemic control in diabetic patients with Escherichia coli urinary tract infection. J Microbiol Immunol Infect. 2013, 46:24-29. 10.1016/j.jmii.2011.12.024

18. Park BS, Lee SJ, Kim YW, Huh JS, Kim JI, Chang SG: Outcome of nephrectomy and kidney-preserving procedures for the treatment of emphysematous pyelonephritis. Scand J Urol Nephrol. 2006, 40:332-338. 10.1080/00365590600794902

19. Geerlings SE, Brouwer EC, Van Kessel KC, Gaastra W, Stolk RP, Hoepelman AI: Cytokine secretion is impaired in women with diabetes mellitus. Eur J Clin Invest. 2000, 30:995-1001. 10.1046/j.13652362.2000.00745.x

20. Kaplan SA, Te AE, Blaivas JG: Urodynamic findings in patients with diabetic cystopathy. J Urol. 1995, 153:342-344. 10.1097/00005392-199502000-00013

21. Mitsumori K, Terai A, Yamamoto S, Yoshida O: Virulence characteristics and DNA fingerprints of Escherichia coli isolated from women with acute uncomplicated pyelonephritis. J Urol. 1997, 158:2329-2332. 10.1016/s0022-5347(01)68244-2

22. Raz R: Postmenopausal women with recurrent UTI . Int J Antimicrob Agents. 2001, 17:269-271. 10.1016/s0924-8579(00)00355-1

23. Garg V, Bose A, Jindal J, Goyal A: Comparison of clinical presentation and risk factors in diabetic and nondiabetic females with urinary tract infection assessed as per the European Association of Urology Classification. J Clin Diagn Res. 2015, 9:PC12-PC14. 10.7860/JCDR/2015/14177.6029

24. Polito M, Minardi D, Montanari MP, Varaldo PE: Adherence of gram negative uropathogens to human uroepithelial cells. Eur Urol. 1987, 13:74-78. 10.1159/000472740

25. Zhou G, Mo WJ, Sebbel P, et al.: Uroplakin Ia is the urothelial receptor for uropathogenic Escherichia coli: evidence from in vitro FimH binding. J Cell Sci. 2001, 114:4095-4103. 